\title{
Sociedad conflictiva en Ozmín y Daraja del Guzmán de Alfarache
}

Hironobu MAKIYAMA

Mateo Alemán intercala "la historia de los dos enemorados Ozmín y Daraja" en su novela Guzmán de Alfarache. La novelita es relatada por un clerigo, que consuela con ella a Guzmán y al arriero que han recibido, sin causa, los puñetazos y golpes de unos cuadrilleros.

Las fuentes de la misma se buscan en la Historia del Abencerraje y de la hermosa Jarifa de autor desconocido, las Guerras civiles de Granada de Ginés Pérez de Hita, la Historia etiópica de Heliodoro y la Cronica de los Reyes Católicos de Hernando del Pulgar./1/ Cualesquiera que fueran sus fuentes, Alemán la situó en el marco concreto de la historia de España al final de la Reconquista, por los años 1489-92, en que desapacieron definitivamente los reinos musulmanes de la península.

Las capitulaciones que los Reyes Católicos concertaron con el rey moro Boabdil, a propósito de la rendición de Granada, fueron generosas para los vencidos, ya que se les permitía conservar la religión, la lengua, la indumentaria y las costumbres tradicionales.

Fiel a estos acuerdos, Fray Hernando de Talavera, primer arzobispo de Granada, practicaba una política de asimilación gradual de los moros al cristianismo, promoviendo la conversión por convicción y previa instrucción del catecismo. El arzobispo recomendaba a los clérigos aprender el árabe para enseñar a los moros el cristianismo en su lengua. A tal propósito, mandó imprimir gramáticas y diccionarios hispano-árabes y traducir la liturgia en árabe. Introducía el castellano como lengua litúrgica e incluso llegaba a utilizaba el árabe cuando lo requerían las circunstancias. Para atraer a la gente a la Iglesia reemplazaba los responsos por los cantos piadosos y sustituía los 
órganos por las "zambas" de músicos moros. Para apartar a los moros psicológicamente de la vida tradicional les regalaba ropas y mobiliario de cristianos./ 2 / Desgraciadamente este método suponía un ritmo lento y trabajoso, $\mathrm{y}$ por conseguiente no dejaba de chocar con la impaciencia de sus colegas.

Cambió radicalmente la política a partir de 1499 cuando Francisco Jiménez de Cisneros, arzobispo de Toledo y primado de España, asumía la tarea con método rápido pero violento. Encarceló a algunos alfaquíes, confiscó los libros arábigos e impulsó la conversión por fuerza y el bautismo en masa. Este método, que violaba las capitulaciones de 1491, provocó varias rebeliones, entre ellas la de las Alpujarras, que el ejercito real tardó tres meses en sofocar. Al cabo de estos incidentes sangrientos, en 1501 los reyes consideraron nulas las capitulaciones y ordenaron a los granadinos vencidos la opción entre el bautismo y la expulsión, ampliando un año después su aplicación a los mudéjares de Castilla y León. La mayoría de ellos no tenían otro remedio que recibir el bautismo, lo cual condujo a numerosas conversiones puramente nominales. Las revueltas de los moros no acaban ahí. El decreto de 1566-67, que les prohibía el uso de la lengua, la indumentaria y las costumbres, provocó la segunda rebelión de las Alpujarras que duró hasta 1570. A raíz de la misma, Felipe II ordenó la dispersión de los moriscos por Castilla.

Teniendo en cuenta estos hechos históricos sucedidos en la rendición de Granada y su etapa posterior, la postura de la reina Isabel de la novela es sumamente significativa. La reina se interesa por la conversión de su cautiva Daraja, que ha traído de Baza, con el argumento de que la mujer de tal calidad y hermosura no tenga el alma fea. La intención de la reina se pone de manifiesto también en las palabras de don Rodrigo a su padre: "siendo la intención de sus Altezas volverla cristiana, y en cuanto Ambrosio allí estuviese, lo tenía por dificultoso" (p. 213). / 3 /

Lo que nos interesa aquí es observar el método que emplea la reina para la conversión de la mora. Es el método de estilo talaveriano, 
la cristianización gradual y apacible, como señala el narrador: "con el deseo que fuese cristiana para disponerla poco a poco sin violencia, con apacibles medios, le dijo" (p. 197). Su proselitismo se limita a pedir a Daraja el cambio de vestidos por los cristianos, que ella misma le regala, lo cual la mora acepta con gusto. Y si la reina deja a Daraja en casa de don Luis de Padilla en compañía de su hija Elvira, no es sólo porque requiere su presencia la empresa militar, sino porque quiere que la mora se vaya acostumbrando gradualmente a la fe cristiana: "para irla saboreando en las cosas de nuestra fe" (p. 198).

Después de diversas vicisitudes, Ozmín y Daraja pueden reunirse en el palacio real de Granada ante los reyes. La reina intenta la conversión, pero respeta la propia decisión de los moros sin forzarles con la obligación o con el castigo; más bien les ofrece la merced: "Pidióles, que si ellos lo querían ser, les haría mucha merced; mas que el amor ni temor los obligase, sino solamente el de Dios y de salvarse, porque de caulquier manera, desde aquel punto se les daba la libertad para que de sus personas y hacienda dispusiesen a su voluntad" (p.242). Ozmín lo acepta de grado, y Daraja contesta vertiendo suaves lágrimas: "pues la divina voluntad había sido darles verdadera luz trayéndolos a su conocimiento por tan ásperos caminos, estaba dispuesta de verdadero corazón a lo mesmo y a la obediencia de los reyes" (p. 242). Los reyes les ofrecen sus nombres para que la pareja reemplace sus nombres musulmanes por ellos, y los honran haciendo de padrinos en el bautismo.

Ahora bien, ¿ esta descripción de la postura de la reina sobre la conversión de Daraja no sería la crítica de Alemán contra la conversión forzosa y violenta que el gobierno propulsaba a finales del siglo XV y a principios del XVI? Nos hemos referido a la política religısa de Gianada no sin razón, porque el narrador mismo llama la atención sobre las conciiciones de la rendición: "ya Granada se había rendido con los partidos que sabemos por las historias y aún oímos a nuestros padres" (p. 237). El clérigo que narra la novelita destaca la notoriedad del hecho histórico. No es un asunto lejano y olvidado. $\mathrm{Ni}$ 
mucho menos; no faltan testimonios escritos $\mathrm{y}$ orales que lo comprueban. Evocando las condiciones de la rendición, nos parece que Alemán acusa a los vencedores del incumplimiento de las mismas, borrón histórico largamente recordado por los moriscos./ 4 /

Así pues, a través de la descripción de la postura de la reina sobre la convdersión y de la alusión a las capitulaciones, creemos que Alemán demuestra su disconformidad con la política oficial de la asimilación.

Ahora bien, la novelita, aunque contiene los amores tiernos de los moros, los actos heroicos de Ozmín en la corrida de toros y la justa, y el final feliz, lleva en el fondo la misma tónica que el relato de las aventuras de Guzmán. El mundo ficticio de Ozmin y Daraja está repleto del engaño, la hipocresía, la asechanza, la murmuración, la envidia, la hostilidad.../ 5 /

Los protagonistas emplean engaños y mentiras, si bien las circunstancias les obligan a tomar tal actitud. La identidad de Ozmín se oculta hasta el desenlace. Finge llamarse Rodrigo de Padilla al ser detenido por un capitán del ejército cristiano a quien aplaca fácilmente con una sortija valiosa. Se llama Ambrosio cuando entra como albañil en casa de don Luis, donde se encuentra Daraja. Ante la insistencia de don Alonso de Zúñiga, Ozmín inventa una historia del cautiverio llamándose jaime Vives y le descubre su amor -falso- a doña Elvira. Así el moro no corresponde a las palabras sinceras de su nuevo amo que jura la amistad y el secreto por su fe y por la orden de caballería.

También Daraja urde mentiras. Cuando don Luis sospecha que Ozmín se introduce en su casa para a raptar a Daraja, crea una historia y le convence vertiendo "algunas eficaces lágrimas" (p. 209). Cuando don Luis pregunta la razón de la llegada de Ozmína la aldea, le entrega una carta previamente preparada diciendo que le envió llamar para que llevara dicha carta a su padre.

Pero si los moros mienten, los nobles cristianos pecan de hipocresía. La actitud de los rivales de don Rodrigo en amores a Daraja se pueden calificar de hipócrita y se subraya que esto ocurre 
más "entre los mejores": "Hablábanle bien, queríanle mal. Vertíanle almíbar por la boca, y dejando en el corazón ponzoña. (...) tal es todo lo que hoy corre, y más entre los mejores" (p. 215).

En la sociedad que rodea a los protagonistas abundan la asechanza y la murmuración, por las cuales Alemán demuestra su obsesiva preocupación a lo largo de toda la novela. La actitud de Ozmín que visita Sevilla en busca de su novia, suscita la sospecha y la murmuración de los vecinos: "todos ponen los ojos en ellos deseando saber quiénes y de dónde son, qué buscan y de qué viven (...) De allí nace la invidia, crece la mormuración, sale de balde el odio, aunque no haya interesados" (p. 202).

La familiaridad entre Daraja y el jardinero origina murmuraciones, que llegan a oídos de don Luis, porque hay quienes pretenden conseguir la privanza con ello. Aquí define la murmuración y denuncia la actitud del vulgo que siempre procura manchar las vidas ajenas:

La mormuración, como hija natural del odio y de la invidia , siempre anda procurando cómo manchar y oscurecer las vidas y virtudes ajenas. $\mathrm{Y}$ así en la gente de condición vil y baja, que es donde hace sus audiencias (...) Esto es lo que el mundo practica y trata, granjear a los mayores a costa ajena, con invenciones y mentiras (p. 205).

Aun en escena coloreada de la justa, podemos ver la referencia a la malicia de los espectadores, puesto que la salida apresurada de Daraja suscita la murmuración de los presentes: "los que con ella estaban se admiraron cómo de alguna cosa no recebía contento y aun lo murmuraban, sospechando cada uno aquello con que mejor se casaba su malicia" (p. 231).

Entre estas observaciones en que se señala la hostilidad de la sociedad, nos llama la atención la descripción nada afable de la gente del campo./6/ Una noche don Alonso y su criado Ozmín visitan una aldea próxima a Sevilla, donde se recrean temporalmente doña Elvira y Daraja. Ozmín, encargado de buscar contactos con las damas, se les acerca cantando en voz baja una canción arábiga para llamar la 
atención de su novia. Al oírla, doña Elvira hace comentarios dirigiéndose a Daraja: "Aun en esta gente bruta puso Dios dones de precio, si supiesen aprovecharse dellos. ¿ No consideras aquel salvaje, qué voz entonada y suave que tiene y va cantando la madre de los cantares? Es como el agua que llueve la mar sin provecho"(p. 233). En realidad, no ha de lamentarse doña Elvira, puesto que esa voz maravillosa no pertenece a un villano cualquiera, sino al moro de sangre real.

Ahora bien, Daraja que reconoce la voz del novio, se une a su amiga en sus críticas contrastando la vida áspera del campo con la vida civilizada de la ciudad:

Estos labradores, por maravilla, si de tiernos no se trasplantan en vida política y los injieren y mudan de tierras ásperas a cultivadas (...) tarde o nunca podrán ser bien morigerados, y al revés, los que son ciudadanos, de política natural, son como la viña, que, dejándola de labrar algunos años, da fruto (p. 233).

Más adelante el narrador se sorprende de la hostilidad de los villanos contra la nobleza, y se lamenta de que ocurran este tipo de discordias entre los seres humanos, y acaba predicando el amor y la fraternidad entre los hombres con el fundamento de la igualdad en la carne, la sangre, el origen, la fe...:

La gente villana siempre tiene la nobleza -por propiedad oculta- un odio natural (...) Que las cosas de diversas especies tengan esto no es maravilla (...) mas hombres racionales, los unos y los otros de un mismo barro, de una carne, de una sangre, de un principio, para un fin, de una ley, de una doctrina, todos en todo lo que es hombres tan misma cosa, que todo hombre naturalmente ame a todo hombre, y éstos haya este resabio, que aquesta canalla endurecida (...) persiga con tanta vehemencia la nobleza, es gran admiración (p. 234)./7/

Estas palabras sirven de introduccón a la descripción de los 
enfrentamientos entre los nobles y los villanos, que a su vez, conduce al desenlace final. Inmediatamente después de la escena de la canción arábiga, los dos enamorados suscitan las escaramuzas con los villanos, que empiezan a atacarlos arrojándoles piedras y les obligan a huir. Don Alonso y su criado vuelven a la aldea a la noche siguiente con la esperanza de seguir sus aventuras amorosas, y esta vez llegan allí más tarde para que los aldeanos no sientan su presencia.

Pero su cautela no les sirve para nada, debido al carácter malicioso de los mismos: "De poco aprovechó, que si rayos del cielo cayeran y con ellos pensaran sus deshechos, había villano en ellos que antes dejara la vida que de guardar el puesto sólo por hacer mal y daño" (p. 235). Los villanos con sus ianzas, palos y azadones en mano reciben su entrada originando gran alboroto. En la pelea, don Alonso queda herido y Ozmín, cautivado después de haber dejado varios muertos y heridos. El narrador comenta los malos tratos (puñadas, rempujones y coces) que de los villanos recibe el moro rendido: "iQué cosa fea y torpe, sólo de semejantes villanos usada como propria!" (p. 236).

En el alboroto interviene la justicia, pero los villanos juran a su antojo torciendo la verdad en su favor. Duras palabras se emplean para criticar esta actitud: "Líbreos Dios de villanos (...) Si dan en perseguir, serán perjuros mil veces en lo que no les importa una paja, sino sólo hacer mal (p. 236). A pesar de los intentos de los villanos, el moro se salva, en la última hora, con la aparición de don Luis, que le trae la orden real de liberación.

Así como se nota, la concepción del mundo rural de Alemán está muy alejada del tópico "Beatus ille" o "Menosprecio de corte y alabanza de aldea", con que los escritores de la época ensalzan la sentillez y la ingenuidad de los pobladores del campo y envidian su contacto con la naturaleza y su vida carente del bullicio mundanal. Las referencias a los villanos en la novelita tienen por objeto destacar insistemente su malicia y su perversividad.

Pero, $i$ de dónde viene tanta inquina del novelista contra el 
campesinado? Creemos que los pasajes siguientes nos ofrecen una posible explicación.

Antes de entrar en la novelita, Guzmán comenta la falta de buen gusto del arriero con el mismo tono y léxico que después va a utilizar doña Elvira. Allí alude a la limpieza de sangre de los villanos y manifiesta, otra vez, la animadversión de ellos contra la clase hidalga:

De mi compañero no hay tratar dél, porque nació entre salvajes, de padres brutos y los paladean con un diente de ajo; la gente rústica, grosera, no tocando a su bondad y limpieza, en materia de gusto pocas veces distingue lo malo de lo bueno. Fáltanles a los más la perfección en los sentidos (...) especialmente en la lengua, aunque no para murmurar, y más de los hijosdalgo (p. 172).

Dice: "no tocando a su bondad y limpieza", pero, $i$ dónde está la bondad de los villanos, ya que se les caractiza por defectos como la bobería, la vileza, la agresividad...? Asimismo la alusión a su limpieza sería otra ironía y mofa del novelista converso sobre el único orgullo de que disfrutaban estos villanos, prototipos de cristianos viejos./ $8 /$.

\section{Notas}

1. Cf. Edmond Cros, Contribution à l'étude des sources de Guzmán de Alfarache, Montpellier, 1967, pp. 13-21 y Donald McGrady, "Consideraciones sobre Ozmin y Daraja de Mateo Alemán”, Revista de Filología Española, 48 (1967), pp. 283-292.

2. Fray Hernando de Talavera, de ascendencia judía, deja claro su pensamiento sobre la conversión en su obra, Católica impugnación publicada en 1487. Se opone tajantemente a la conversión por fuerza: "Y el judío, ni moro, no prometió lo contrario de aquello que guarda; y porque sería traerlos a la santa fe por fuerza, lo cual no se debe hacer en ninguna manera especialmente en los adultos, quia caetera potest homo nolens, credere autem non nisi volens" (ed. F. Martín Hernández, Barcelona, Juan Flors, 1961, p. 171). Sobre la vida y la obra de Fray Hernando, cf. F. Márquez Villanueva, "Estudio preliminar" a dicha obra e Investigaciones sobre Juan Alvares Gato, Madrid, Real Academia Española, 1974, pp. 105-154.

3. Para las citas del Guzmán de Alfarache seguimos la edición de Francisco Rico, 
Barcelona, Planeta, 1983.

4. Cf. Julio Caro Baroja, Los moriscos del reino de Granada, Madrid, Istmo, 1976, p. 48.

5. Guido Mancini dice al respecto: “proyectando en otra atmósfera la misma problemática del pícaro, establece una nueva y vivaz o, por lo menos, una nuevo motivo de meditación" ("Consideraciones sobre Ozmín y Daraja, narración interpolada”, Prohemio, 2-3 [dic., 1971], pp. 417-437; p. 432).

6. En la novela algunos villanos aparecen como objeto de burlas, calificados con nombres despectivos de asno y bestia (pp. 500 y 647). Si estos pertenecen a cuentos tradicionales de las bobadas de aldeanos, en el libro de Alemán faltan otros cuentos fundados en la agudeza de los villanos que abundan en la tradición oral y los libros de los cuentistas (Timoneda y Santa Cruz) como señala Maxime Chevalier. Cf. "Guzmán de Alfarache en 1605: Mateo Alemán frente a su público", Anuario de Letras, 11 (1973), pp.125-147.

7. La misma exigencia de la igualdad de la sangre y el linaje aquí expresada se puede encontrar en los escritores conversos. Para Fray Luis de León las condiciones de los súbditos del reino son "ser generosos y nobles y de un mismo linaje (...) Y assí, todos son hechuras y nascimiento del cielo, hermano entre sí hijos todos de Christo" (De los nombres de Cristo, ed. Cristóbal Cuevas, Madrid, Cátedra, 1982, pp. 374-375). Juan Luis Vives también se refiere a la igualdad del origen humano: "Todos nuestros cuerpos son hechos de uns masa, todos de unos mismos elementos (...) menospreciar la bajeza del linaje es en cierta manera encubiertamente culpar a Dios" (Introducción a la sabiduria, en Obras escogidas de filosofos, Madrid, Atlas, 1953, p. 241). Américo Castro comenta esta angustia de los conversos ante la sociedad discriminatoria referente a los pasajes de Fray Luis: "Los cristianos nuevos venían blandiendo defensivamente, desde el siglo XV, el argumento de no hacer Dios la diferencia entre unos y otros cristianos" ( $L a$ realidad histórica de España, México, Porrúa, 1973, p. 283).

8. Ya han advertido este pequeño detalle Joseph H. Silverman, "Los hidalgos cansados de Lope de Vega" en Homenaje a William L. Fichter, Madrid, Castalia, 1971, pp. 693-711; p. 701, nota 30, y Benito Brancaforte, ed. Guzmán de Alfarache, Madrid, Cátedra, 1979, I, p. 172, nota 25. La creencia campesina de su limpieza de sangre se basaba en la ausencia casi total de los judíos en su estasmento por las actividades burguesas y urbanas de éstos. Américo Castro ha demonstrado cómo el campesinado se convierten en el "último refugio contra la ofensiva de la 'opinión"' (De la edad conflictiva, Madrid, Taurus, 1972, p. 175). 